Journal of Engineering and Applied Sciences 15 (2): 437-443, 2020

ISSN: 1816-949X

(C) Medwell Journals, 2020

\title{
Web-Based Expert System for Sustainable Urban Transportation [ESSUT]
}

\author{
${ }^{1,3}$ Mohammed Ali S. Wafi, ${ }^{1,2}$ Muhamad Nazri Borhan, ${ }^{1,2}$ Riza Atiq Abdullah O.K. Rahmat and \\ ${ }^{1,4}$ Hamza Imhimmed Mohamed Irtema \\ ${ }^{1}$ Centre for Smart and Sustainable Township Research Centre (Sutra), \\ ${ }^{2}$ Programme of Civil Engineering, Faculty of Engineering and Built Environment, \\ Universiti Kebangsaan Malaysia, Kuala Lumpur, Malaysia \\ ${ }^{3}$ College of Engineering Technology, Houn, Libya \\ ${ }^{4}$ Department of Civil Engineering, Sebha University, Sabha, Libya
}

\begin{abstract}
The sustainable development is the subject that gained a grown interest from several developing countries which aim is approaching the problems related to economic, environmental and social impacts. There are parameters that act as key measures in assessing the sustainability of the transport system to identify the vital impact. In the current study, a Sustainable Urban Transportation system (ESSUT) is proposed as a method for transport experts that provides effective solutions and policies through the help of a web-based expert system. To design a system, MySQL and PHP languages were utilizedas a backend database with CSS adopted for the interface which is an application with important information and services for construction of windows or web-based applications. Through, the adoption ESSUT, an online consultant system can improve effectively and facilitate the engineers, civil engineering students as well as decision-makers with recommendations and determining solutions to get sustainable urban transportation.
\end{abstract}

Key words: Expert system, sustainable urban transportation, ESSUT, MySQL and PHP languages, CSS adopted, web-based applications

\section{INTRODUCTION}

Even though the sustainability concept was widely discussed in literature, there is lack of proper definition of this term. In addition, although, there are various definitions and sustainability approaches, the majority of academic researchers acknowledge the significance of the 'Brundtland Report' and utilize its definition of sustainable development as a beginning point for further investigation. Actually when considering sustainable development, the key contemporary construction industry concerns include ecological effect, societal equity and economic development.

The worldwide urban population in 2006 had outgrown the worldwide rural population for the first time in history. The population of new cities more than the former lives in slums which are mostly quite far from their services, schools and jobs. This quick urban population increase in large number of cities hasled to strain of existing public transit networks and made it increasingly uneasy to walk and cycle making passengers buy and acquire personal motorized vehicles for their daily transportation use. While the urban population has largely grown within the developing world, the motorization has expanded dramatically which has caused issues such as air pollution (Colvile et al., 2001) and traffic congestion (Downs, 2005).

The aim of the research is to determine an expert system for sustainable urban transportation for developing countries. The expert systems are referred to smart information system which performs in some cases as a human expert in the application domain (Waterman, 1986a, b).

\section{Literature review}

Sustainable transport: The conventional transportation planning presumes that transport enhancements are linear. This linear form is viewed as transport modes which replace the slower and older forms with more fast and advanced forms. The sustainable transport is reflecting a parallel model by assuming that every mode plays a significant role. In addition, the sustainable transport provides a balanced transportation system which utilizes all types of transportation services optimally. Therefore, the transport sustainability aims at enhancing the overall quality of the existing transport modes in an optimized and balanced way while not only focusing on modern and advanced transport (Litman and Burwell, 2006). The

Corresponding Author: Mohammed Ali S. Wafi, Centre for Smart and Sustainable Township Research Centre (Sutra), Faculty of Engineering and Built Environment, Universiti Kebangsaan Malaysia, Kuala Lumpur, Malaysia 
major challenge, however, in sustainable transport is to identify the suitable strategies to implement within a city based on the categories of geographical area. The reason of it because in certain cities, the most effective strategy for sustainable transport can include enhancements to walking and cycling modes, better support of public transport and restriction of crowded urban areas to private transport. The selection and identification of a suitable strategy in accordance to the geographical area of course is a hard challenge for educators who do not have direct involvement in the site.

Expert system civil engineering: The expert system refers to the current information technology skill that is derived from Artificial Intelligence Research of Civil Engineering field several years ago. It needed development was for mimicking or replicating the problems in a computer software such as road accidents, smart air pollution and traffic congestion. Various expert systems in the transportation-engineering field had recent advancement.

KBES: The KBES is expert system created with a menu driven type that is based on open source programs with three very significant web development tools which are: Apache for web server, PHP [Hypertext Preprocessor] for scripting " $\mathrm{C}$ " program language and MySQL for management of database. This system helps the user to choose congestion or road crash prone areas exact location using an interface in which a series of questions regarding the problems causes leading to potential traffic control alternative solutions. The testing of the expert system was done in two local isolated intersections in Quezon city, Philippines to validate signalized and unsignalized three-legged intersection. As a result, KBES recommended increasing right turning radius of the corner pavement for signalized intersection for trucks in order to avoid delay and conflicts between vehicles while the latter intersection recommended a left turn prohibition at major approach in order to avoid approach collisions and delay (De Guzman and Sigua, 2011).

DATLCES: In his research, Wen developed a knowledge-based expert system, DATLCES which facilitates to automatically optimize and manage the traffic lights cycle length in urban areas through the cooperation with a simulating model which is comprised of six various models to make the system analyze traffic issues. DATLCES can enhance the time of inter-arrival and inter-departure of vehicles at intersections and provide the adjustment of timing and phasing for traffic lights.

E-ACTIVERANS: E-ACTIVERANS is a specialist system that facilitates the experts to set portability administration methodologies a specific end goal which influences a change from latent to dynamic transport mode such as cycling and strolling, through perceiving the transportation specialists perspectives regarding the most suitable techniques in accordance to the change from mechanized transport to dynamic transport (Salleh et al., 2015).

CALMSYS: CALMSYS expert system aids the unexperienced transport engineers to optimize the well-being problems that are connected to activities in private gatherer lanes and private neighborhoods where end users are motivated to locate their own problems with the help of the system offering an important counsel. This expert systemaims at covering the suggestions and arrangements which can be related to reduce the negative impact of mechanized vehicles, trip generator regions and much of the time mischance focuses (Falamarzi et al., 2014).

USLIMITS: This is the expert system that is relevant for all kinds of streets which range from rustic streets to urban interstates. The system makes the users in the neighborhood offices, groups and structural specialists set the rate limitation without the need to involve specialists. USLIMITS analyses data by identifying the various components such as for instance, 85 th percentile rapidity, accident history, movement capacity and roadway attributes which the users need to fill.

TRALI: TRALI is a system that facilitates the movement engineers in setting an activity signal for disengaged convergences. The expert system learning base depends on creation rules. The activity volume experts which can be allocated to the system are not restricted. Moreover, boulevards (Zozaya-Gorostiza and Hendrickson, 1987) could change the movement path and various methodologies.

Micro PAVER: The US Army Corps Engineers developed another pavement management expert system. Micro PAVER aims to facilitate the engineers to maintain the military roads. The key objective of this system is to run on personal desktops while PAVER can work on the mainframe computers. The system is used in administering airfield pavement, roads, streets and parking lots and focuses on projects that are based on real elements including: the available funds, repair type, repairs and maintenance costs (Ismail et al., 2009a, b).

TRSys: Online consultant Web-Based Expert System (TRSys) has been developed to ensure the optimization of traffic road in developing countries in order to help road traffic experts on determining the effective and appropriate policies for the development dealing with traffic-related issueneeds. TRSys facilitates the contractors, engineers, civil engineering students, consultants and traffic safety decision-makers who have beneficial commendations suitable to road network, to 
determine traffic complications and accordingly use the suitable solutions to reduce noise and air pollution on main roads (Alshetwi et al., 2018).

COPRBU: COPRBU is a knowledge-based expert system developed and programmed based on Microsoft Visual Basic to deal with the problems related to schedules and routes of public transportation system including administration of operational issues of public buses. The study based on questionnaire surveys where the participants were users and person-in-charge of public buses (Mosa et al., 2013).

SP-SPEDA: The sustainable development expert system is called Sistem Pakaruntuk Strategi Pengangkutan Bandar Mapan (SP-SPEDA) which is developed for urban transport strategy andcreated using Microsoft Visual Basic. The objective of this system is to provide sustainability and professionalism of urban transport through computer based on applications for private transportation engineers and planners, engineers and transportation who are lack of technical knowledge and have no experience. The professionals can use this system to share their field knowledge, get useful information from reference magazines, books, interview with dominant professionals and field visitations (Ladin et al., 2013).

Knowledge-based expert system for intersection improvement: De Guzman and Sigua (2009) developed a knowledge-based expert system that aims to upgrade safety measures taken at intersections with key goal of replacing micro-simulation programs to improve road safety at intersections. The objective of developing this system is to upgrade intersections through the reduction of number of congestions and traffic accidents and this method was found to be useful for students, consultants, government agencies and civil engineers.

USLIMITS2: In their research, Srinivasan et al. created USLIMITS2 which is a web-based expert system that provides reasonable speed barriers on US expressways in accordance to the Federal Highway Administration (BIWA) regulations and is based on the out comes derived from previous studies and the data received from surveying users on present USLIMITS program which has been developed by the Australian Roads Research Council.

\section{MATERIALS AND METHODS}

The presents study identified the system as the Expert System for Sustainable Urban Transport System [ESUST] by agreeing on the development of a knowledge-based expert system. The programming language used in the PHP system development to provide a high tracking capability and adaptability to quickly develop this prototype. This infiltration allows the knowledge engineer to provide domain knowledge much easier. Furthermore, the programming languages development need to time as the developer should first familiarise with the terminology of the computer and must continue to improve the codes of a program. That is important to develop (GUI) Graphical User Interface for the system. Therefore, CSS was implemented for the interface. As stipulated by Gilmore, the development language has been used (Preprocessor Hypertext-Processor) PHP with MySQL as the basic database for the main engine of the system. The development language has been used PHP and MySQL as a basic database with implemented CSS for the interface in designing such a system in developing, a web-based application was chosen these two sources are based on their flexibility, modularity and capabilities. Moreover, program debugging often is challenging (Waterman, 1986a, b; Alshetwi et al., 2018).

Knowledge acquisition: Knowledge acquisition is the most important stage of developing expert systems because successful knowledge acquisition can make the correct expert system, otherwise the result may not be suitable and profitable for use (Patel and Ranganathan, 2001). Firstly, knowledge must be collected from current sources such as books and relevant experts. Knowledge engineering is established to elicit knowledge from proficient experts from relevant literature including books, manuals, research papers and other useful textbooks. Knowledge can also be gathered by carrying out interviews with the domain experts and mandatory that these interviews must be analysed, revised and then used as the domain knowledge (Mosa et al., 2013; Pomerol, 1997). Numerous sources of knowledge have been indicated and integrated to develop the current knowledge base of the expert system. Figure 1 exemplifies the knowledge attainment flow diagram and view these sources and provide a comprehensive explanation of each.

Selection of building tool: The establishment of an Expert System for Sustainable Urban Transportation

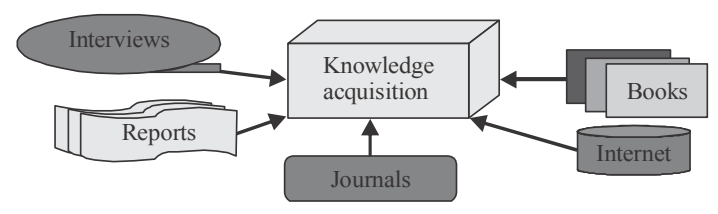

Fig. 1: Knowledge acquisition flow diagram 
(ESSUT) to implement the sustainable urban transportation strategies of transport system provides a number of tools required once developing a user interface. The utilised software version is Adobe Dreamweaver CC 2015 release which is used to create the expert system. This software eases the experience of uploading whole web site to a web server. The development of web-based expert system is mainly dependent on end-user interface Graphical User Interface (GUI) and server site programming designs, particularly the site where the knowledge-based rules are a programming task. Moreover, a responsive web interface to assist the browsing from mobile devices is ensured by the Bootstrap framework. Agent process or a proxy manages the extraction of data from the web page on the server side. The relational database used for storing the gathered information is MySQL which is a patented, modified entry-level SQL employment that has the capacity and tools for simplifying the build expert systems and building operations, thus, leading to cost-effectiveness of the process (Milad et al., 2017; Mansyur et al., 2011).

Knowledge representation: The usage of attained knowledge such as PHP is a symbolic representation of dealing with an automatic means over the logic expert system. A suggested technique used in this expert system is for the detection of user's guide and problems over on the diagnostic process with the first step of engineers and experts to collect the basic evidence on the case followed by the decision-making process. Therefore, for this expert system, the forwarding inference engine concatenation is sufficient as an episodic alternative with logic rises from given of information and carrying on with it. This method is following to IF-THEN relations procedures which can be shown as IF (Status), then (Conclusion). Rules can be aggregated by engaging contact conditions including OR and another constitutes aggregated rules or composite rules. This approach depends on the relation IF-THEN. That is if a situation matches the IF condition in a general rule, the procedures on the THEN side should be applied. This process can be modelled as IF the case, THEN the conclusion (Alshetwi et al., 2018).

Expert system architecture: An expert system is a form of the computer programs forms that represent and reasoning knowledge by a specialized subject as it provides advice or solves problems and often known as knowledge engineering with the participation of the knowledge engineer with the components of the expert system in full. Expert systems building is an iterative approach including improved components action by the course of many knowledge engineers meetings with the experts and user (Hubka and Eder 2012).

ESSUT structure consists of an inference engine, working memory, knowledge base and graphical user interface. The system structure building by an engineer of knowledge is with the knowledge acquisition and reasoning approaches from domain experts and written sources. Figure 2 shows ESSUT structure.

Graphical user interface: A graphical user interface offers a means for humans to interact with a machine. User interface collects the information needed by the machine to complete the decision-making process by querying the user in responding to questions or providing additional specific information. A well-designed user interface is of great benefit to users because reduces the time required for users familiarize them selves with the system and it has the capacity in reducing the occurrence of mistakes while using the expert system. PHP was the platform used to build the expert system: it is necessary for developers to generate several items or pages in the PHP environment (Alshetwi et al., 2018). Expert System for Sustainable Urban Transportation (ESSUT) graphical user interface is pleasant and easy to use. Clarity and attractiveness can facilitate the utilization of the system. Figure 3 exemplifies the design window illustrations.

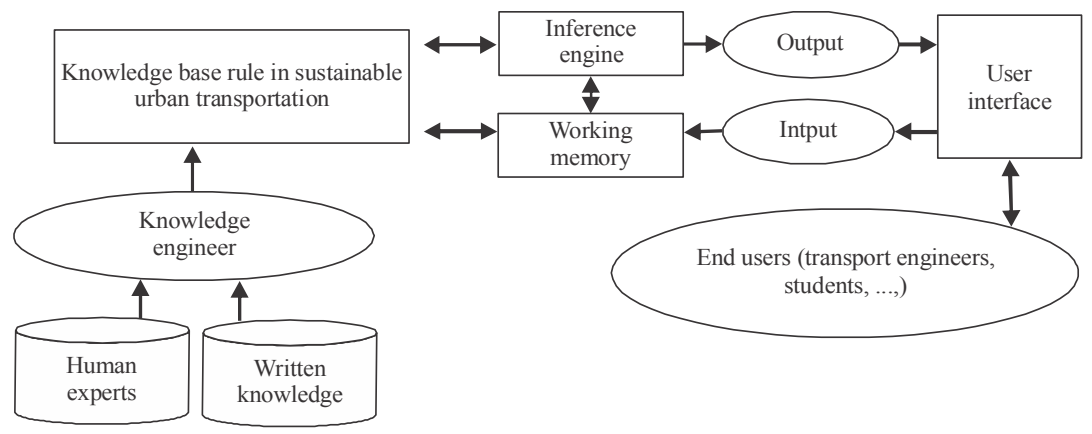

Fig. 2: The structure of ESSUT 


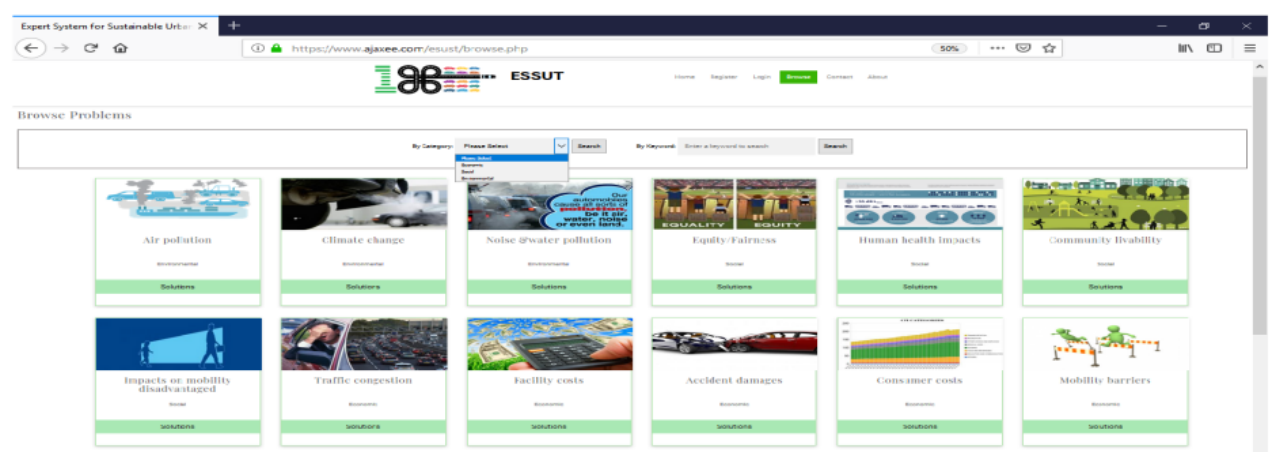

Fig. 3: A screenshot of the ESSUT main menu

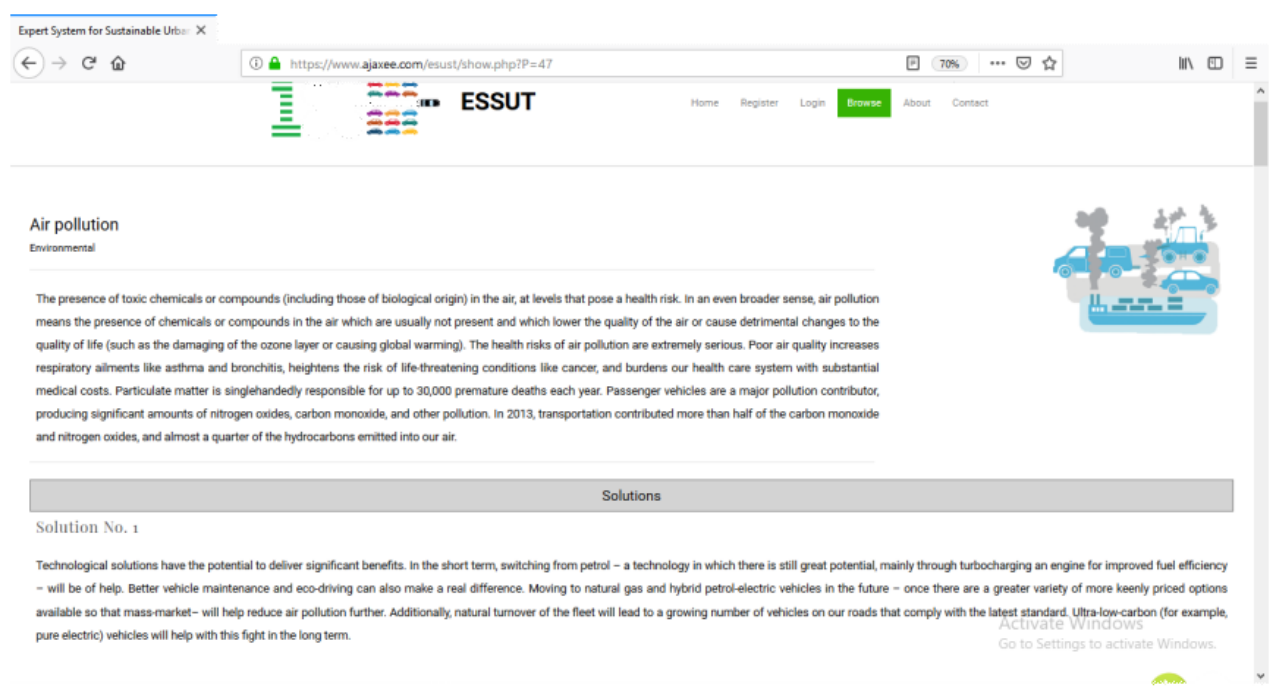

Fig. 4: A screenshot of the problem and solutions page

Toolbox for environmental: The presence of air pollution means the presence of chemicals or compounds in the air which are usually not present and which lower the quality of the air or cause detrimental changes to the life quality (such as the causing global warming or the ozone layer damage) are exactly serious. Poor air quality increases respiratory illnesses such as bronchitis and asthma, increases the life-threatening risk diseases such as burdens and cancer in our health care system with significant medical costs. Passenger cars are a major contributor to pollution, producing large amounts of carbon monoxide, oxides, nitrogen and other pollution in the air. Were previously in Fig. 4 presented and described to users. The solutions to technology such as a shift from gasoline technology which has a great prospect, most of them are more of a turbo charged engine to improve fuel efficiency, vehicle maintenance and environmental-drivingsuch as natural gas and hybrid petrol-electric vehicles in the future to curb air pollution. Ultra-low-carbon [for instance, pure electric] vehicles will aid with this battle in the long term.

\section{RESULTS AND DISCUSSION}

Evaluation of the system: The system evaluation in the study was carried out in order to assess the overall system acceptance by its end users. Additionally, the end users who include students, inexperienced engineers and decision-makers as well have to be satisfied with the system performance. The respondents were questioned regarding usefulness once dealing with transport issues including the problems with the transport and strategies of urban sustainable transportation, user-friendliness, learnability, efficiency, system consistency, overall assessment, determining technical issues and recommending the system to other users. In the current study, the questionnaire surveys were provided to the 21 respondents. According to the resultsof analysis that are demonstrated in Fig. 5, the majority of respondents stated that the system is useful, properly createdas per the existing technical problems and user friendly. Additionally, over $90 \%$ of participants has agreed to 


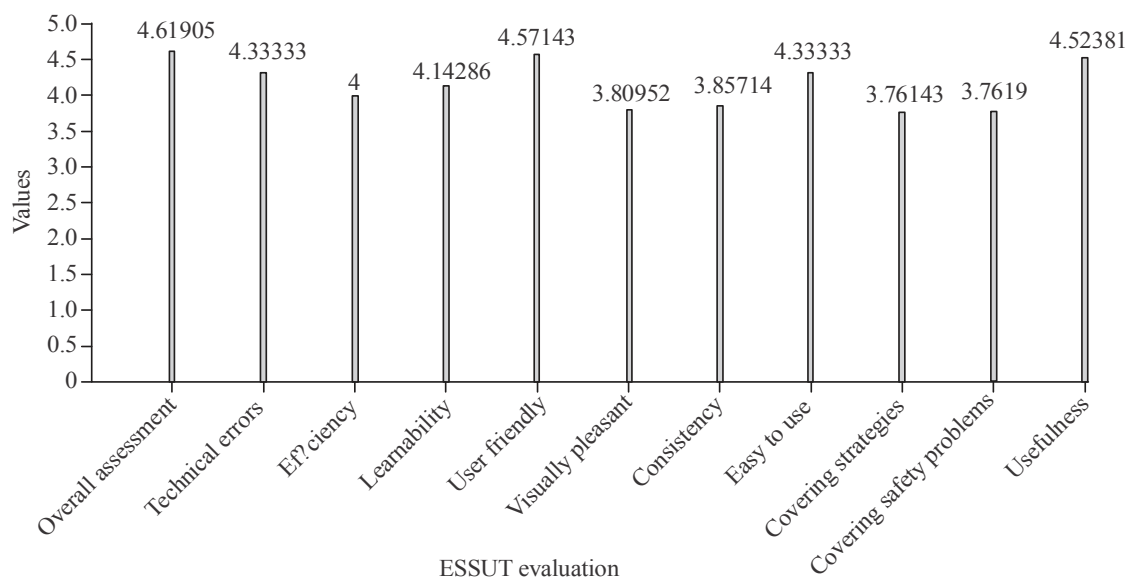

Fig. 5: Results of ESSUT evaluation

recommend the system in the future due to innovations and the benefits of the system. The result of assessment was more than 4 which means the system has achieved its goal.

\section{CONCLUSION}

The current study describes online consultant system web-based Expert System (ESSUT) for Sustainable Urban Transportation in developing countries that provided a procedure for transport experts by creating advertising and guidance and adopting required policies. The development of sustainable urban transportation that deals with the issue that are related to transportation requires different skills and knowledge gathered from sources, like technical reports, books, manuals and standards and overview of transport experts. The computer tool utilisation in creating the expert system, web-based expert system (PHP) is an application that mostly contains vital abilities while building a windows or web-based applications, for example, expert systems and provide tools rapidly and effectively. This advance Expert System (ESSUT) offers various benefits to operators and engineers by providing approvals appropriately, facilitates the junior engineers in their studies, students and decision-makers in identifying transport complications and applying appropriate solutions based on transportation problems impact on sustainability issues in developing countries.

\section{ACKNOWLEDGEMENT}

The research presented in this study was supported by College of Engineering Technology Houn, Libya and Center for Smart and Sustainable Township Research Center (SUTRA), Faculty of
Engineering and Built Environment, Universiti Kebangsaan Malaysia (UKM) Malaysia, Under the Project GUP-2016-019.

\section{REFERENCES}

Alshetwi, A.B., M.N. Borhan, S.I.A. Ali, H.I.M. Irtema and B. Mohashhash et al., 2018. Prototype webbased expert system for optimizing the road network of developing countries. J. Eng. Sci. Technol., 13: 4053-4065.

Colvile, R.N., E.J. Hutchinson, J.S. Mindell and R.F. Warren, 2001. The transport sector as a source of air pollution. Atmospheric Environ., 35: 1537-1565.

De Guzman, M.P. and R.D.G. Sigua, 2009. Development of a knowledge-based expert system for intersection improvement. Proc. East. Asia Soc. Trans. Stud., 7: 1-16.

De Guzman, M.P. and R.D.G. Sigua, 2011. Application of a knowledge-based expert system to alleviate traffic congestion and road crashes at intersections. J. East. Asia Soc. Transp. Stud., 9: 1-16.

Downs, A., 2005. Still Stuck in Traffic: Coping with Peak-Hour Traffic Congestion. Brookings Institution Press, Washington, D.C., USA., ISBN: 9780815796558,.

Falamarzi, A., M.N. Borhan and R.A.O. Rahmat, 2014. Developing a web-based advisory expert system for implementing traffic calming strategies. Sci. World J., 2014: 1-16.

Hubka, V. and W.E. Eder, 2012. Design Science: Introduction to the Needs, Scope and Organization of Engineering Design Knowledge. Springer, Berlin, Germany, ISBN:13-978-3-540-19997-7, Pages: 251. 
Ismail, N., A. Ismail and R. Atiq, 2009a. An overview of expert systems in pavement management. Eur. J. Sci. Res., 30: 99-111.

Ismail, N., A. Ismail and R.A.O.K. Rahmat, 2009b. Development of expert system for airport pavement maintenance and rehabilitation. Eur. J. Sci. Res., 35: 121-129.

Ladin, M.A., S.I. Albrka, H.A. Yahia, A. Ismail and R.A.A.O. Rahmat, 2013. Development an expert system towards sustainable transportation (E-st) for students. Proceedings of the Malaysian Universities Transport Research Forum Conference, December 23-24, 2013, Bangi, Malaysia, pp: 1-9.

Litman, T. and D. Burwell, 2006. Issues in sustainable transportation. Intl. J. Global Environ. Issues, 6: 331-347.

Mansyur, R., R.A.O.K. Rahmat, A. Ismail and M.R. Kabit, 2011. Decision support system for transport demand management: Object oriented approach using kappa PC 2.4 expert system shell. ARPN. J. Eng. Appl. Sci., 6: 73-81.

Milad, A., N.E.A. Basri, H.M. Abdelsalam and R.A.A.B.O. Rahmat, 2017. Prototype web-based expert system for flexible pavement maintenance. J. Eng. Sci. Technol., 12: 2909-2921.
Mosa, A.M., R.A.O. Rahmat, A. Ismail and M.R. Taha, 2013. Expert system to control construction problems in flexible pavements. Comput. Aided Civil Infrastruct. Eng., 28: 307-323.

Patel, M. and N. Ranganathan, 2001. IDUTC: An intelligent decision-making system for urban traffic-control applications. Veh. Technol. IEEE. Trans., 50: 816-829.

Pomerol, J.C., 1997. Artificial intelligence and human decision making. Eur. J. Oper. Res., 99: 3-35.

Salleh, B.S., R.A.O. Rahmat and A. Ismail, 2015. Expert system on selection of mobility management strategies towards implementing active transport. Procedia Soc. Behav. Sci., 195: 2896-2904.

Waterman, D.A., 1986a. A Guide to Expert Systems. Pearson, London, UK., ISBN:9788131713310,.

Waterman, D.A., 1986b. A Guide to Expert Systems. 1st Edn., Addison-Wesley Publishing Company, Inc., USA.

Zozaya-Gorostiza, C. and C. Hendrickson, 1987. Expert system for traffic signal setting assistance. J. Transp. Eng., 113: 108-126. 